\title{
MÍDIA E PROCESSO PENAL: INFLUÊNCIA MIDIÁTICA NAS DECISÕES PROFERIDAS PELO TRIBUNAL DO JÚRI
}

\author{
Larissa Aparecida Costa
}

Centro Universitário Toledo de Presidente Prudente, Presidente Prudente, SP. E-mail: lari costa93@hotmail.com

\section{RESUMO}

Com vistas a efetivar a democracia, o constituinte atribuiu competência ao Tribunal Popular, para os crimes dolosos contra a vida. O presente estudo trata da possível influência que a mídia exerce sobre os jurados que compõem o Conselho de Sentença, que devem proferir seu voto por meio de seu livre convencimento acerca das provas apresentadas em plenário, de forma imparcial. Analisando a atuação midiática frente à sociedade globalizada verifica-se que a imparcialidade resta comprometida em alguns casos, onde muitas vezes o julgamento é transferido do plenário do Júri, para os meios de comunicação. Inegável a importância dos meios de comunicação, o direito de liberdade de expressão, de onde decorre o direito de liberdade de imprensa, mecanismo essencial para a consolidação do Estado Democrático de Direito, contudo os excessos cometidos no legitimo direito de informar, podem causar lesão aos direitos e garantias dos acusados.

Palavras-chave: Tribunal do Júri. Jurados. Presunção de Inocência. Liberdade de Imprensa. Influência Exercida pelos Meios de Comunicação. Estado Democrático de Direito. Colisão entre Direitos Fundamentais.

\begin{abstract}
In order to accomplish democracy, the constitutional competence attributed to the People's Court, for crimes against life. This study deals with the possible influence that the media has on the jurors who make up the Council of Judgement, which should deliver his vote through its free conviction on the evidence presented in plenary impartially. Analyzing media performance across the global society there is that impartiality remains compromised in some cases, often where the trial is transferred from the jury plenary to the media. Denying the importance of the media, the right to freedom of expression, which follows the right to freedom of the press, essential mechanism for consolidating the democratic rule of law, yet the excesses committed in the lawful right to inform, can cause injury to rights and guarantees of the accused.
\end{abstract}

Keywords: Jury. Jurors. Presumption Press Inocência.Liberdade. Having exercised influence by the Media. Democratic state. Collision between Fundamental Rights. 


\section{INTRODUÇÃO}

Diante do processo de globalização e a evolução tecnológica, verificou-se uma nova forma de interação da mídia e a sociedade. Com o advento das mídias de massa, constata-se que a atuação midiática, está cada vez mais presente na vida social.

Com vistas a assegurar direitos e garantias fundamentais, surgiu o Tribunal do Júri, conferindo a qualquer cidadão, a prerrogativa de aplicar a justiça de acordo com seu convencimento, livre de qualquer manipulação ou interferência.

A imprensa tem o importante papel de junto com a comunidade fiscalizar a atuação dos poderes públicos. Contudo, a problemática se dá ao estabelecer limites frente a abusos e excessos no direito de informar, que frequentemente entram em conflito com outros direitos, garantias e liberdades, tutelados constitucionalmente e de grande importância para o estado democrático de direito, quanto à liberdade de imprensa e a liberdade de expressão.

Frente a este panorama, o presente estudo analisa a possível interferência da mídia nas decisões do Tribunal do Júri, e a suscita a colisão de direitos fundamentais.

\section{METODOLOGIA}

O trabalho de pesquisa se utilizará do método dedutivo a fim de compreender a crescente interferência midiática na vida social, por meio do método de pesquisa indireta bibliográfica e jurisprudencial.

\section{MÍDIA E PROCESSO: COLISÃO DE DIREITOS FUNDAMENTAIS}

Em uma sociedade democrática, os meios de comunicação além de informar, buscam propor debates, interagem com a população, propagam noticias e esclarecem os fatos sociais, e a partir dessa interação, o homem exerce sua condição de ser integrante do corpo social, pensando e exteriorizando suas ideias e recebendo informação.

À medida que o indivíduo se comunica, desenvolvendo suas potencialidades e aptidões, atua de forma positiva na sociedade, contribuindo com ela.

Quando a imprensa sofre limitações no seu direito de informar, a sua função social fica comprometida, mas nenhum direito é irrestrito, assim também a liberdade pressupõem limites. A busca pelo conhecimento e informação, inerente à natureza humana, torna-se essencial para o convivo e manutenção da sociedade. 
Nesse contexto Aluizio Ferreira (1997, p.80):

A necessidade de informação é a mais básica das necessidades humanas, constituindo-se o direito à ela num direito fundamentalíssimo, porquanto pressuposto de todos os demais. Deter informação é questão de sobrevivência tanto individual (física,emocional e psíquica) quanto social e política. Não é apenas o homem atual que se acha condicionado pela necessidade de conhecimento ou informação. O homem sempre esteve a isso condicionado e não poderá jamais deixar de assim estar.

Com a maior complexidade das sociedades, os acontecimentos sociais, ganharam maior importância na vida das pessoas e destaque por parte dos meios difusores de informação.

Como bem observa Fábio Konder Comparato (2005, p.391), “maior influência exercerá o interlocutor que dispuser de mais e melhores informações na situação estabelecida, e com maiores probabilidades ele contará de afirmação de seus interesses e pretensões", dando ensejo à premissa que "informação é poder". O Estado Democrático, consolidado, sobretudo pela participação dos cidadãos nos rumos do país, necessita da publicidade dos atos do governo para se efetivar.

Dessa forma, verifica-se que a publicidade aos atos processuais, concede visibilidade a população, e permite a participação dela. Assim, a informação, transformada em noticia, foi ganhando cada vez mais espaço no cotidiano do cidadão, a medida que os meios de comunicação se desenvolviam.

A relação entre imprensa e justiça criminal, há muito tempo instiga a curiosidade popular. Nos dias atuais, esse fenômeno adquire relevância ainda maior, tendo em vista a atuação intensa da mídia - jornais, revistas, rádio, televisão, internet - exercendo assim o "quarto poder" nas sociedades democráticas.

A liberdade concedida aos meios de comunicação, a fim de informar a sociedade, deve ser a mais ampla possível, contudo, não pode violar os princípios basilares do processo penal, criando um pré-julgamento público e sem o devido processo legal.

Assim, se torna imprescindível e difícil delinear limites à liberdade de imprensa frente à publicidade do processo penal. Inegável, portanto, a contribuição da mídia na manutenção do sistema democrático de participação e controle popular, contudo, quando o direito de informar invade a privacidade, intimidade, expondo a imagem do suspeito, acaba por ferir a presunção de inocência e demais garantias processuais. 
A mídia, ao expor o suspeito, sua vida privada, sua imagem, e detalhes da investigação, muitas vezes, acaba por criar um julgamento público antecipado, que não atende aos requisitos legais, nem mesmo aos preceitos constitucionais.

A esse respeito $\mathrm{TUCCI},(1999$, p. 113) discorre:

Na tensão dialética entre, de um lado, a liberdade de imprensa e de outro, por exemplo, a presunção de inocência, o que se tem visto com espantosa frequência é o perecimento da presunção de inocência, avassalada por uma pressão de mídia, que se tresmalha dos limites do razoável e do justo.

A pressão da mídia acaba por convencer os jurados, antes mesmo de que a estes sejam apresentadas formalmente as provas levantadas, o que torna a expressão "por seu livre convencimento" um tanto quanto viciada.

Ao decretar a condenação pública do suspeito, a imprensa acaba por exercer grande poder e manipulação sobre a opinião de pessoas que invariavelmente serão os jurados escolhidos para julgar o fato criminoso. Sendo assim, tais pessoas recebem previamente, por parte da mídia, diversas informações que, na maioria das vezes, não condizem com a realidade e que irão influenciá-las na hora do julgamento. Acerca das "verdades" veiculadas pelos meios de comunicação, assim discorre Felipe Pena (2007, p. 113):

Os julgamentos são influenciados pela formação e, também pelo que os meios de comunicação nos apresentam como verdade. Somos cruéis em nossos julgamentos. Na maioria das vezes, esquecemos que eles são mediados. Se não forem pela imprensa, podem ser pelos nossos próprios preconceitos, pelo inconsciente ou pela linguagem. [...] os maniqueísmos se apresentam e o veredicto se resume à velha luta entre o bem e o mal. Só que os indivíduos são muito mais complexos do que isso.

Restringir a analise do fato a partir das noticias publicadas pela mídia, é limitar a produção de provas e o direito de defesa do acusado. Assim, quando a mídia atua noticiando circunstâncias e eventos íntimos da vida do suspeito, presumindo culpas, atua de forma prejudicial ao desenvolvimento do processo e pode viciar a imparcialidade dos julgamentos.

Sobre o tema assim se posiciona TUCCI (1999, p. 115).

Indubitável é que a pressão da mídia produz efeitos perante o juiz togado, o qual se sente pressionado pela ordem pública, por outro lado, de maior amplitude é este efeito sobre o júri popular que possui estreita relação com a opinião pública construída pela campanha midiática, é obvio, pois, que isto faz com que a independência do julgador se dissipe não podendo este realizar um julgamento livre por estar diante de uma verdadeira coação. Levar um réu a julgamento no auge deu ma campanha de mídia é levá-lo a um linchamento, em que os ritos e fórmulas processuais são 
apenas a aparência da justiça, se encobrindo os mecanismos cruéis de uma execução sumária.

Em relação a possível influência da mídia nos jurados que compõem o conselho de sentença, assim afirma BASTOS, (1999, p. 117):

[...] se a pressão e a influência da mídia tendem a produzir efeitos sobre os juízes togados, muito maiores são esses efeitos sobre o júri popular, mais sintonizado com a opinião pública, de que deve ser a expressão. [...]. Com os jurados é pior: envolvidos pela opinião pública, construída massivamente por campanhas da mídia orquestradas e frenéticas, é difícil exigir deles conduta que não seguir a corrente.

Os meios de comunicação que massivamente noticiam os crimes e os atos violentos, tornando-se um aliado da população no conhecimento da situação atual. Dessa forma, sentindo-se "amparada" por uma mídia que informa e noticia tudo o que ocorre no país e no mundo, a população não se atenta aos excessos e abusos que podem eventualmente ocorrer no exercício do direito de informar. Entretanto, o que se verifica na sociedade contemporânea não é a tutela a publicidade dos atos processuais ao advogado, à vitima ou ao indiciado. Portanto, cabe avaliar que no mais das vezes a publicidade se desenvolve a fim de atender a interesses jornalísticos, criando uma "espetacularização" da atividade investigatória.

Nesse sentido Adauto Suamnes $(1999$, p.158) assim se posiciona:

(...) a finalidade do inquérito não é nem pode ser a de causar vexames a pessoas, donde deve a autoridade policial agir com o máximo de discrição, pois tudo que ela tem em mãos é uma hipótese de trabalho, uma classificação provisória - seja quanto ao enquadramento dos fatos, seja quanto ao possível autor deles - que somente após o crivo do Ministério Público e a concordância do Poder Judiciário justificará os inconvenientes de um processo judicial.

Cabe ressaltar que do mesmo modo que a mídia pode auxiliar o trabalho policial; em certos casos quando divulgam de forma detalhada, toda a ação investigatória, podem prejudicar o andamento das investigações. Outro ponto importante da atuação da mídia é o tratamento e a exposição do indiciado, sua imagem e vida privada são devassadas de maneira indevida. Carnelutti (1995, p.45), discorre sobre os eventuais abusos na atuação da imprensa:

A crônica judiciária e a literatura policial servem, do mesmo modo, de diversão para a cinzenta vida cotidiana. Assim a descoberta do delito, de dolorosa necessidade social, se tornou uma espécie de esporte; as pessoas se apaixonam como na caça ai tesouro; jornalistas profissionais, jornalistas diletantes, jornalistas improvisados são tão colaboradores quanto fazem concorrência aos oficiais de policia e aos juízes instrutores; e, o que é pior, ai 
fazem o trabalho deles. (...) O homem, quando é suspeito de um delito, é jogado as feras (...) Logo que surge o suspeito, o acusado, a sua família, a sua cara, o seu trabalho são inquiridos, investigados, despidos na presença de todos, O individuo, assim, é feito em pedaços (...) embora fosse o único valor que deveria ser protegido.

A publicidade sob a ótica do acusado torna-se um direito e uma garantia a regularidade e segurança do procedimento, favorecendo o direito de defesa. É por meio da publicidade processual que o acusado acompanhar e controlar os atos, participando ativamente efetivando do processo para tutelar seus direitos, assim tutela legal as garantias mínimas a fim de se obter um processo justo e sem mácula.

Por outro lado, o acusado é o centro da notícia, criando assim o estereótipo do criminoso, dando ensejo em nome da "justiça" a um espetáculo punitivo público, a fim de julgar o acusado, não the concedendo o devido processo legal, a ampla defesa e sem observar o principio da presunção de inocência. Assim detalhes mais íntimos da vida privada do acusado tornam-se públicos, mesmo que não possuam relevância para a busca da verdade real, em grave violação a dignidade humana do indivíduo.

Portanto, resta claro a importância dos meios de comunicação no regime democrático e no próprio desenvolvimento da personalidade humana. Porém, ao atuar deliberadamente, invadindo as esferas pessoais, lesando a honra e a privacidade do acusado, torna-se um instrumento prejudicial ao sistema penal.

O processo penal deve ser conduzido com responsabilidade por parte dos sujeitos processuais, sejam juízes, membros do MP ou advogados, cautela que deve se estender também na divulgação da noticia pela mídia.

Não se pode buscar legalizar a censura, mas que os direitos e liberdades aqui em choque liberdade de imprensa e garantias legais do acusado - se harmonizem, apesar do panorama atual mostrar difícil.

\section{CONCLUSÃO}

O presente trabalho discorreu acerca da possível interferência da mídia nos processos judiciais, em especial sobre os jurados, nos casos de crime doloso contra a vida, com previsão de competência do Tribunal do Júri.

As considerações feitas demonstram a dificuldade em encontrar a harmonização entre a liberdade de imprensa e os direitos personalíssimos do acusado no processo penal. Isso se dá, pois após delinear os bens em conflito, se faz necessário buscar alternativas para harmonização, 
ponderando, no caso concreto, sob a ótica constitucional qual representa o valor mais relevante no caso concreto.

Obstar a participação da mídia nos procedimentos penais, impedindo a veiculação de noticias, ou impondo censura a sua atuação, é um retrocesso que não se compatibiliza com a sociedade democrática atual. Contudo, o processo deve ser instrumento de garantia da liberdade do individuo, norteando-se pela guarda da dignidade da pessoa humana, a fim de se obter um justo processo.

É legitimo e essencial à divulgação dos atos da Justiça pela mídia, cumprindo assim seu direito de informar os cidadãos sobre os delitos e a atuação do judiciário. Mas como nenhum valor ou principio resta absoluto por integrar o texto constitucional, é forçoso concluir que a harmonização é imprescindível para que um não se sobreponha a outro.

A atuação midiática sobre a opinião pública acaba por atingir, aqueles que irão compor o conselho de sentença, e assim altera a formação de sua livre convicção a cerca do crime, recebendo informações, que por vezes, não condizem com a realidade dos fatos.

Diante de todo o exposto concluiu-se que, embora a liberdade de manifestação do pensamento e da informação seja de extrema importância para a garantia da democracia, esta não pode ter primazia absoluta quando seu exercício sacrificar a intimidade, a honra ou a imagem do acusado ou investigado.

Sendo assim, e por ser o júri, talvez, a única esfera do poder judiciário permeável à efetiva intervenção da sociedade, imperioso que o mesmo se aperfeiçoe para que possa se adequar frente à realidade de nossa sociedade tecnológica e globalizada.

\section{REFERÊNCIAS}

ALEXY, Robert. Teoria dos Direitos Fundamentais. Tradução de Virgílio Afonso da Silva. 2. ed. São Paulo: Malheiros, 2011.

AMARAL, Márcia Franz. Jornalismo popular. São Paulo: Contexto, 2006.

BARATTA, Alessandro. Filosofo de uma criminologia crítica. In: Silvia Ramos.Org. Mídia e violência urbana. Rio de Janeiro: Faperj, 1994.

BASTOS, Márcio Thomaz. Júri e mídia. In: Tribunal do júri: Estudo sobre a mais democrática instituição jurídica brasileira. São Paulo: Revista dos Tribunais, 1999.

CARNELUTTI, Francesco. As misérias do processo penal. Tradução J. Cardinalli. São Paulo: Conan, 1995. 
COMPARATO, Fábio Konder. Afirmação Histórica do Direitos Humanos. 4.ed.São Paulo: Saraiva, 2005.

DWORKIN, Ronald. Levando os Direitos a Sério. Tradução de Nelson Boeira. São Paulo: Martins Fontes, 2002.

FERREIRA FILHO, Manoel Gonçalves. Direitos humanos fundamentais. 7ạ ed. São Paulo: Saraiva, 2005.

FERREIRA, Aluizio. Direito à informação, direito à comunicação, São Paulo, Celso Bastos/IBDC, 1997.

JABUR, Gilberto Haddad. Liberdade de pensamento e direito à vida privada: conflitos entre direitos da personalidade. São Paulo, SP: Revista dos Tribunais, 2000.

KELSEN, Hans. A Democracia. 1. ed. São Paulo: Martins Fontes, 1993.

PEREIRA, Guilherme Doring Cunha. Liberdade e responsabilidade dos meios de comunicação São Paulo: Editora Revista dos Tribunais, 2002.

PIOVESAN, Flávia. Direitos Humanos e o Direito Constitucional Internacional. 4.ed.São Paulo: Max Limonad, 2000.

SUAMNES, Adauto. Os fundamentos éticos do devido processo penal. São Paulo: RT, 1999.

TORRES, Ricardo Lobo. Teoria dos Direitos Fundamentais. 2‥ ed. Rio de Janeiro: Renovar, 2004.

TUCCI, Rogéria Lauria. Tribunal do júri. Estudo sobre a mais democrática instituição jurídica brasileira. São Paulo: Editora Revista dos Tribunais, 1999.

VIEIRA, Ana Lúcia Menezes. Processo penal e mídia. São Paulo: Editora Revista, 2003. 